\title{
MANAGERIAL GUIDELINES FOR MARKET PENETRATION AND EXPANSION: A CASE STUDY OF A MEDICAL DEVICES MANUFACTURER
}

\author{
Juppa, V.
}

This article brings managerial guidelines for new market expansion and current market penetration on the example of a Czech medical devices manufacturer. We describe the strategy in evaluation of the opportunities in the territories, of setting up the benchmarks, the steps how to deal with partners in current territories and how to approach the acquisition of new territories. We show how significant the sales growth is for financials, and we mention the limit defined in the Theory of Sustainable Growth. We show how important the level is, how the products are advanced and how important it is to have unique products. The objective of the article is to bring a basis for new thoughts to readers who might intend to look for new markets acquisition. The information and facts provided show a real example of an existing company's approach.

JEL Classification: M1, M3

Keywords: market penetration; expansion; management; guidelines

\section{Introduction}

The Czech economy is traditionally an open one; export and international cooperation are inevitable characteristics. There is a dependency on the European market as one third of Czech export is directed to Germany. Despite the fact that the government, ministries, governmental agencies and associations are developing more and more sophisticated tools for export support, many companies face problems in acquiring new markets and entering new territories.

This text brings the marketing strategy aspects of a Czech company, which is a medical device manufacturer. The article brings years of long experience, from strategy concept and implementation. The company focuses above all on medical devices for internal medicine, i.e. devices generally used and accepted by the experts; the number of high quality manufacturers worldwide is limited. The products are manufactured under the conditions of European legislation, are CE marked and meet European conformity criteria. The product size is reasonable as is the expiry; this is why the logistics are not complicated. The big advantage is that the company has its own unique products, which are desired by experts and this opens the global market.
The principles applied, ideas, lessons learned and open questions might be interesting for the representatives of other businesses to think over in terms of modification of their intentions.

\section{Territory potential evaluation, benchmarks setting and acquisition}

The major desire of the company is to broaden the market and increase sales, which is crucial for the company's following growth. This corresponds with the ideas developed by Kotler and Keller (2006). The volume of sales increase is desired as the manufacturing base is well established, in-house R\&D is developed and this currently results in a high proportion of fixed costs in the complete cost structure. The sales increase is expected to also allow optimization of the procurement, manufacturing, planning and maintaining stock, packaging, batching for purchased services like sterilization, allowing for standardization on a certain level, optimizing of the product portfolio, making forecasts, etc. We will come back to this topic later.

The company adopted its own "bearskin” philosophy; each tip of the pentagon represents one of the tasks how to increase the total sales volume (see figure 1). 
Figure 1: Strategic priorities of the company

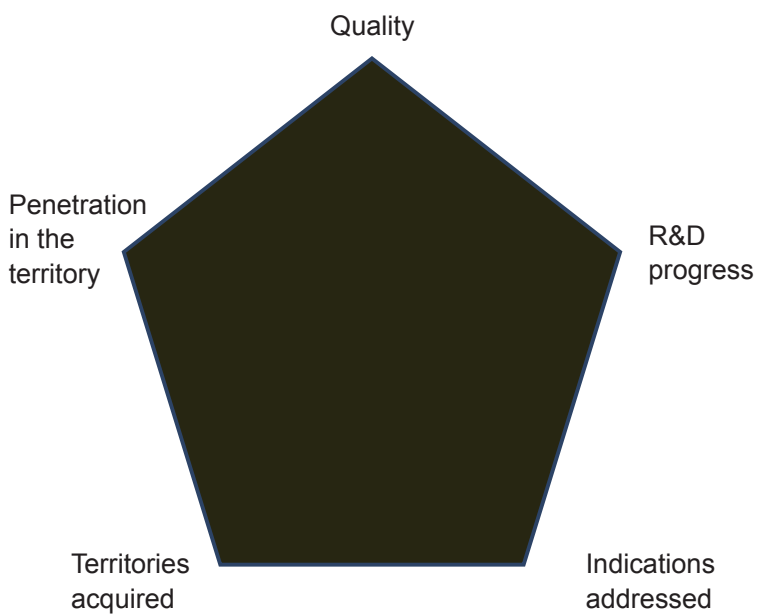

Source: Author

The company uses a systematic approach when deciding which territory to pay attention to; a systematic approach is applied at the potential of the territory's assessment. The company came to the evaluation method through a multi-criteria analysis involving the relevant data (see figure 2). The first premise for the potential of the territory's assessment is - in the medical field we can assume that the incidence of diseases, the number of cases of particular indications results from statistics how populous the country is; in other words, the larger the population, the larger the number of patients who can be treated by a particular method. That helps make the first very simple view of the territory and its estimated market potential. On the other hand, there are a number of factors affecting the reality, which must be taken in consideration.

For each country in the model we know the population and spending on healthcare; we can record additional criteria for later consideration. Once we proceed in our analysis and consideration, we record our findings and recommended steps for selected territories as well.

The company proceeds in the following steps:

1) As mentioned already, the countries are listed, sorted into groups by size and economic potential measured by the GDP/capita ratio, and the spending on healthcare is entered.

2) The real sales in current acquired territories are entered (columns Sales 2010, Sales 2011).

3) The ratios on sales related to the population (auxiliary indicator) are calculated and from the countries with well-developed businesses, the five with the best penetration (highest sales volume pro population) are selected. We do not take just the star; we want to have more objective figures.

4) The hypothetical expected sales are calculated for each country using the above mentioned ratio (auxiliary indicator) and population in each particular country. This helps us have the first (far from perfect) benchmark for each territory calculated from the real current figures.

5) Territories with evident disadvantages are excluded from next consideration; they remain in the table of course (low potential, distant, with evident barriers, etc.)

6) For the other territories we start collecting data, which will be exploited for more specific estimates and expectations as to the opportunities. We collect information on the centers and experts in a given medical discipline, the progress, practices, habits and general principles in the discipline, demographic structure, social groups and wealth distribution, access to the health care, position of the competition, competitive products; we will also discover and assess barriers such as administrative, custom, technical, logistic ones, etc.

7) The evaluation and consideration of that set of information helps us further specify the expectations and achievable benchmarks and to conceive our strategy.

8) We discover the countries with high demands on registration, requiring large clinical trials (USA, Japan, Korea), countries with very uneven wealth distribution, where only part of the population might be considered comparable with developed countries (India, South Africa, China), countries with hidden administrative barriers (France), countries with severe competition (Korea), countries with low IP protection and high risk of patent infringement (China), countries distant but still interesting (New Zealand), tiny countries which are still interesting despite their small size (Slovenia), countries with different frequencies of a particular indication (lower incidence of colon cancer in the Arabic world), etc.

9) The strategy is to respect all the findings in our current territories (primarily the volume comparisons), to define the steps to improve our position and to define the responsibilities to proceed. The data and analysis results can be used in meetings with partners. We understand their territory better and have arguments while negotiating the sales volumes.

10) The strategy then has to respect the findings in the next potential territories of our interest and has to define the priorities as to next territories to acquire; 
Figure 2: Model for estimation of a territory's potential (the numbers are just illustrative)

\begin{tabular}{|c|c|c|c|c|c|c|c|c|c|c|c|c|}
\hline \multicolumn{6}{|c|}{ STRATEGY IN TERRITORIES } & & & & & & & \\
\hline \multicolumn{5}{|c|}{ Objective criteria } & \multicolumn{8}{|c|}{ Peneration in the market } \\
\hline Country & Population & $\begin{array}{l}\text { GDP per } \\
\text { capita }\end{array}$ & $\begin{array}{l}\text { additional } \\
\text { criteria }\end{array}$ & $\begin{array}{l}\text { Health } \\
\text { care } \\
\text { spendings } \\
\text { USD/ } \\
\text { capita/ }\end{array}$ & $\begin{array}{l}\text { sales } \\
2011\end{array}$ & $\begin{array}{l}\text { Sales } \\
2012\end{array}$ & $\begin{array}{l}\text { Sales } \\
2012 \\
/ \\
2011\end{array}$ & \multicolumn{2}{|c|}{$\begin{array}{l}\text { hypotetic sales } \\
\text { five best } \\
\text { benchmark }\end{array}$} & $\begin{array}{c}\text { sales } 2012 \\
/ \\
\text { benchmark }\end{array}$ & \multicolumn{2}{|c|}{$\begin{array}{l}\text { hypotetic sales } \\
\text { five best } \\
\text { benchmark } \\
\text { corrected }\end{array}$} \\
\hline & persons & th USD & & & mil Kč & mil Kč & $\%$ & mil Kč & mil EUR & $\%$ & mil Kč & mil EUR \\
\hline \multicolumn{13}{|c|}{$\begin{array}{l}\text { Large countries with the highest } \\
\text { econ.potential }\end{array}$} \\
\hline USA & 306,0 & 47 & & 6014 & 0,8000 & 0,70 & 87,50 & 64,91 & 2,60 & 1,08 & & \\
\hline Japan & 127,4 & 34,3 & & 3120 & 1,9000 & 4,20 & 221,05 & 27,03 & 1,08 & 15,54 & & \\
\hline Germany & 82,0 & 40 & & 3162 & 8,6000 & 8,90 & 103,49 & 17,39 & 0,70 & 51,17 & & \\
\hline Great Britain & 60,9 & 45,7 & & 3322 & 9,2000 & 10,40 & 113,04 & 12,92 & 0,52 & 80,50 & & \\
\hline Italy & 60,0 & 35,7 & & 3022 & 1,1000 & 0,90 & 81,82 & 12,73 & 0,51 & 7,07 & & \\
\hline Spain & 46,2 & 32 & & 3027 & 4,2000 & 7,10 & 169,05 & 9,80 & 0,39 & 72,45 & & \\
\hline \multicolumn{13}{|c|}{\begin{tabular}{l|l|l} 
etc. & \\
\end{tabular}} \\
\hline \multicolumn{13}{|c|}{$\begin{array}{l}\begin{array}{c}\text { Middle size countries with the highest } \\
\text { econ.potential }\end{array} \\
\end{array}$} \\
\hline Netherlands & 16,50 & 54 & & 5123 & 0,6000 & 0,40 & 66,67 & 3,50 & 0,14 & 11,43 & & \\
\hline Sweden & 9,20 & 55,6 & & 3757 & 2,1000 & 2,30 & 109,52 & 1,95 & 0,08 & 117,85 & & \\
\hline Austria & 8,30 & 44,8 & & 3397 & 1,8000 & 1,90 & 105,56 & 1,76 & 0,07 & 107,91 & & \\
\hline Swiss & 7,70 & 67,4 & & 5394 & 0,8000 & 1,10 & 137,50 & 1,63 & 0,07 & 67,34 & & \\
\hline \multirow{2}{*}{\multicolumn{13}{|c|}{$\begin{array}{l}\text { etc. } \\
\text { Small countries with the highest econ. } \\
\text { potential }\end{array}$}} \\
\hline & & & & & & & & & & & & \\
\hline Ireland & 5,90 & 58,9 & & 3704 & 0,2200 & 0,00 & 0,00 & 1,25 & 0,05 & 0,00 & & \\
\hline Denmark & 5,50 & 67,4 & & 4564 & 0,7200 & 0,93 & 129,17 & 1,17 & 0,05 & 79,71 & & \\
\hline Finland & 5,30 & 46,8 & & 3332 & 0,1000 & 1,49 & 1490,00 & 1,12 & 0,04 & 132,53 & & \\
\hline Norway & 4,80 & 102 & & 4082 & 0,0000 & 0,00 & $!$ & 1,02 & 0,04 & 0,00 & & \\
\hline etc. & & & & & & & & & & & 0,00 & 0,00 \\
\hline \multicolumn{13}{|c|}{$\begin{array}{c}\text { Large countries with lower economic } \\
\text { potential }\end{array}$} \\
\hline Brasil & 196,0 & 6,9 & & 427 & 0,0000 & 0,00 & $!$ & 41,58 & 1,66 & 0,00 & 20,00 & 0,80 \\
\hline Russia & 142,0 & 12,5 & & 369 & 4,3000 & 5,10 & 118,60 & 30,12 & 1,20 & 16,93 & 0,00 & 0,00 \\
\hline Mexico & 109,0 & 10,7 & & 500 & 0,3400 & 0,39 & 114,71 & 23,12 & 0,92 & 1,69 & 0,00 & 0,00 \\
\hline etc. & & & & & & & & & & & & \\
\hline \multicolumn{13}{|c|}{$\begin{array}{c}\text { Middle size + small countries with } \\
\text { lower econ. potential }\end{array}$} \\
\hline Chile & 17,0 & 14,7 & & 473 & 0,0000 & 0,00 & $!$ & 3,61 & 0,14 & 0,00 & 0,00 & 0,00 \\
\hline Angola & 16,9 & 6,4 & & 71 & 0,0000 & 0,00 & $!$ & 3,58 & 0,14 & 0,00 & 0,00 & 0,00 \\
\hline Kaza chstán & 15,2 & 6,8 & & 189 & 0,0700 & 0,08 & 114,29 & 3,22 & 0,13 & 2,48 & 0,00 & 0,00 \\
\hline etc. & & & & & & & & & & & & \\
\hline \multicolumn{13}{|c|}{ Countries with low GDP / capita } \\
\hline China & 1300,0 & 3,2 & & 90 & 0,0000 & 0,00 & $!$ & 275,77 & 11,03 & 0,00 & 0,00 & 0,00 \\
\hline India & 1140,0 & 0,94 & & 39 & 2,9000 & 2,93 & 101,03 & 241,83 & 9,67 & 1,21 & 20,00 & 0,80 \\
\hline Ma rocco & 31,3 & 2,4 & & 95 & 0,0000 & 0,00 & $!$ & 6,64 & 0,27 & 0,00 & 0,00 & 0,00 \\
\hline etc. & & & & & & & & & & & & \\
\hline
\end{tabular}

Source: Author 
it has to define the ways to get in contact with the partners there as well as how to project that into business development (see further).

11) The data precision and completion, evaluation and analysis might be done in several cycles; in each of them, we should get a new and more precise basis for our consideration.

In current territories, the calculated and then corrected benchmarks help us see how good we are in the territory; then we can split the volumes into particular products and methods and see their success. Using this data, we can deal with the partner, discuss the reasons and look for corrective provisions. We will provide the partner with additional training for their sales staff, accompany them on visits to key opinion leaders (KOLs), help them with the information and promotion of the methods at the KOLs, discuss potential assistance in the first cases, informational support, provide them with publications and help build contact to the KOLs in other countries. We learn from their experience with competitive products or alternative methods (the alternative methods can be used because of the level of health care spending, habits etc.). We will discuss with our partner our participation in their promotion activities, participation in conferences, exhibitions, potential use of the products in live cases at conferences. We will learn from our partner about the situation in tenders for important institutions, about potential competitors, learn about the lost opportunities and the reasons and we have to discuss the price policy for particular tenders. This all helps us understand the final customers' attitude.

The stability in the relationships with current partners, when we are not solving any severe problem, helps us focus our sales potential on service quality and on new acquisitions.

For potential new territories of our interest, priorities should be defined. We will definitely pay attention to USA, Russia, China, India, Japan etc. if they are not among our current territories. We will study, in detail, the opportunities and barriers and set up the tasks to overcome the barriers; we will also set up the time horizon. The big players with their potential affect our entire business. All the territories which are interesting for us should be kept in mind when at international conferences and exhibitions while meeting with experts, while looking for them in the participants lists, while using recommendation from others, or while collecting contacts during conferences or exhibitions. Promising contacts are to be matched with the strategy for a particular territory and exploited properly in compliance with the strategy. At the same time, we have to look for the most prestigious centers in a given medical discipline, identify the key opinion leaders (from publications, references) and get in contact with them. Further, we look for potential business partners in the role of distributors. We get in contact with the embassy, with the Czech ministries, Czech governmental agencies and ask for their assistance in the territory. We define the way to get in contact with the KOLs in order to get the chance to present our products and methods. The chance might be meeting them at international conferences, invitation to our exhibition during the conference, direct contact and visit, contact and visit with the help of the representatives of the embassy or governmental agency, etc. While talking to the KOLs, we ask their advice and recommendations regarding who might be a good distributor, who serves their institution. In addition, we ask the embassy or governmental agency for help as to potential distributor identification and contact arrangements. We have prepared a business development plan including contract concept, files and information for registration, information support, visits plan, volume benchmarks (see above), price list and price policy as to discounts, free samples etc. This all is used in the dealings with the potential partner while negotiating the future business and expected achievements.

Some countries might be served by our partner from another country, i.e. the combination of markets is something worth thinking about. This is why we do not forget the territories which do not seem to be attractive enough at first sight, but might be taken in consideration while developing business with the partner in a "neighboring country".

\section{Importance of the sales growth for the financials and company development}

Using the above described model helps us define the strategy for each particular territory, define the steps, timing, responsibility, etc. What's more, the model allows us to estimate the overall expectations, to define the business plan for the company, plan sales and make plans and provisions in manufacturing, stock planning, procurement optimization etc. - in the time perspective. The volume plans help us further specify the calculations and apply the proper pricing policy. A business with highly developed R\&D, strong innovation, and diverse markets has costs structure with a high portion of fixed costs. This is why every change in sales affects the financial result - profit creation. The sales volume increase allows better dissolution of fixed costs and higher financial effect (see figure 3). 
Figure 3: Importance of sales volume growth on the financials

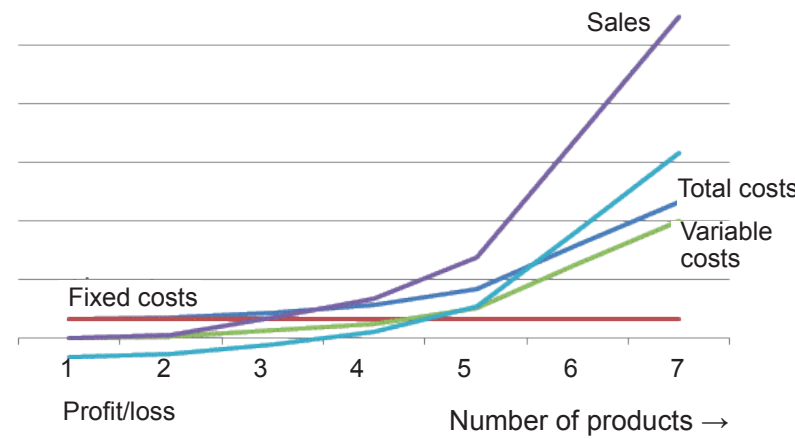

Source: Author

This effect brings us back to the pricing policy as we have the space for price reconsideration. We can lower the prices in general. However, a more effective method is to conceive new principles in the discounts, which can be used for the quantity discounts, for particular product sales support or for free samples for special cases supporting our promotion in the territory. These free samples might be used for clinical trials, breaking barriers in some territories and might be used for studies resulting in publications.

The financial effect helps the profit creation which, on one side, can be spent for R\&D or manufacturing, or on the other hand can be capitalized. That capitalization is a very important issue as it goes hand in hand with the strategy of sales increase. With respect to the Theory of Sustainable Growth defined by Higgins (2008), the theory consists of calculations taking into consideration the sales volume growth, profitability, taxation, dividend pay out, necessary growth in assets and respective structure of liabilities, as well as the price of purchased sources of financing.The calculation determines the maximal percentage of sales growth. That means if our profitability and retained profit portion is higher, the sales (generally business volume) growth might also be higher.

\section{Innovation and advanced products and methods as a key to market acquisition}

The success in new partners' acquisition in the territories, the success in dealing with the KOLs and the products and methods used are not self-explanatory. As known also from literature (Cho, Pucik 2005), there are several other aspects which play a key role in achieving success; for example: how advanced are the products and methods in terms of clinical aspects, the competitiveness of the products and methods in terms of progress of the procedure, the quality of manufacturing and reliability, the availability of the product and related services and support, and last but not least is the pricing. It is necessary for the company to understand the position of each product or product type and to know the position in comparison to competitive products and to alternative methods. It is necessary to know whether the national legislation and medical guidelines recognize the method and whether the doctors are willing and even allowed to use the method in their country. Based on this knowledge, the products can be positioned into the pyramid according to their above mentioned aspects (see figure 4).

Figure 4: Pyramid of products according to their uniqueness

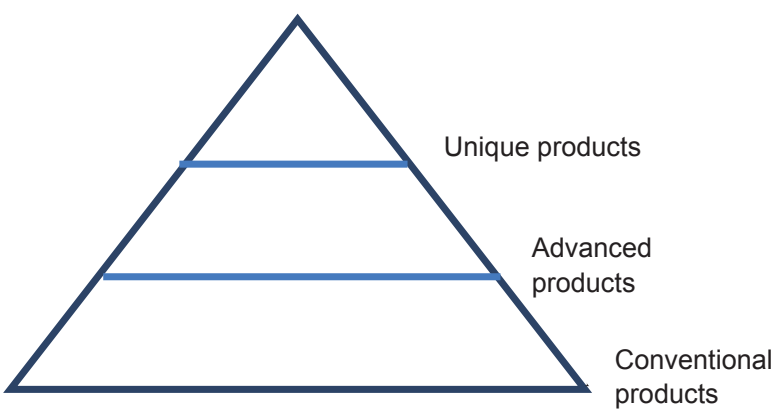

Source: Author

Unique products are those which do not have competitors, where the medical procedure is unique, and the IPR as to the technical aspects is protected. The company is a manufacturer of some products with these characteristics, i.e. they are the results of in-house R\&D. The products are the door openers; they are the first promoted and the first used at the company introduction. These products make the market global for the company.

Advanced products are those which might have competition in the products and methods of similar characteristics, and the products have more advanced features than those of competitive products. These products are also a matter of promotion, while the advanced features and advantages for the user are stressed.

Conventional products have competition and belong to the group of products of similar characteristics; they have to be in the portfolio to complete the range in the offer and to meet as many of the needs of the experts as possible.

The promotional activities, dealing with partners, dealing with the experts in their discipline exploit then mix of the 
information, the information on unique products are the core of that information mix. The unique products are the door openers. Also while dealing with the embassies and ministries, we have to stress the key advantages that help them build desired contacts.

The salesmen dealing with the partners, dealing with the experts, visiting conferences and exhibitions should systematically collect data on competitive products, data on the opinion of the experts on the methods, on alternative methods, as well as data on their desires. All this data is important for $\mathrm{R} \& \mathrm{D}$, for the promotion concept and also for the pricing policy. They must result in new developments and in a fair understanding of our position. This process can be seen as one corresponding to the methods described by Kotler and Keller (2006).

That brings us back to the bear skin philosophy mentioned above.

\section{Conclusion}

The article provided managerial guidelines for new market expansion and current market penetration on an example of a Czech medical devices manufacturer. We demonstrated the effort spent while applying the strategy of penetration in current markets and the strategy of new market acquisition. The article demonstrates the importance of new market acquisition for business growth, for improvement of the financial ratios and generally for the company's further development. The following are very important aspect: innovations, the attention paid to new products and development of methods. Advanced and unique products are the door opener to the partners and final users. These lessons are valid for the representatives of other different businesses; the guidelines might help them generate their own approach.

\section{References}

Cho, H. J., Pucik, V. (2005). Relationship between innovativeness, quality, growth, profitability, and market value. Strategic Management Journal, 26: 555-575.

Higgins, R. C. (2008). Analysis for financial management, 9th ed. New York: McGraw-Hill.

Kotler, P., Keller, K. L. (2006). Marketing Management, 12th ed. New Jersey: Pearson Education.

Author

Vlastimil Juppa

Marketing and Foreign Affairs

ELLA-CS Hradec Kralove

vlastimil.juppa@tiscali.cz 